\section{O desafio da descentralização do Sistema Único de Saúde em município de grande porte: o caso de São Paulo, Brasil}

\author{
The challenge of decentralization of the Unified \\ National Health System in large cities: the case \\ of São Paulo, Brazil
}

Sandra Maria Spedo 1,2

Oswaldo Yoshimi Tanaka 1

Nicanor Rodrigues da Silva Pinto 1,2

\footnotetext{
${ }^{1}$ Faculdade de Saúde Pública, Universidade de São Paulo, São Paulo, Brasil. 2 Escola Paulista de Medicina, Universidade Federal de São Paulo, São Paulo, Brasil.

Correspondência S. M. Spedo Departamento de Medicina Preventiva, Escola Paulista de Medicina, Universidade Federal de São Paulo. Rua Botucatu 740, São Paulo, SP 04023-900, Brasil. smspedo@medprev.epm.br
}

\begin{abstract}
Decentralization of Brazil's Unified National Health System (SUS) still poses challenges in large cities. To characterize decentralization as an essentially political process, institutional policy variables, including local management capacity, are determinant for shaping decentralization in each context. Using the government triangle reference to evaluate management capacity, a case study was conducted with the objective of analyzing the system's decentralization in the city of São Paulo, Brazil's largest metropolis. An analysis of selected health system managers and administrative documents identified a trend towards focusing health management at the municipal level in 2005-2008, accompanied by dismantling of local/regional structures in the Municipal Health Secretariat, resulting in technical and policy depletion at these levels. Despite the limits of decentralization, the article emphasizes its power as an operational strategy to achieve the SUS' objectives. The article also stresses the need to resume the health decentralization process in the city of São Paulo, both moving towards local/ regional levels and linked to the decentralization of municipal public management.
\end{abstract}

Decentralization; Health Management; Health Policy; Single Health System
Introdução

A descentralização do sistema e serviços de saúde implementada no Brasil, a partir da década de 1990, representou importante avanço no sentido da construção do Sistema Único de Saúde (SUS) 1,2,3. No entanto, deve-se considerar que esse processo foi impulsionado e induzido pelo Ministério da Saúde por meio da edição de sucessivos instrumentos normativos, as Normas Operacionais Básicas do SUS (NOB), editados a partir de 1991, o que foi caracterizado como um "certo jeito NOB de fazer o SUS, esculpindo-o a golpes de portaria" 4 (p. 293). A rigidez normativa e o detalhamento excessivo desses instrumentos representaram limitações à operacionalização da descentralização mediante uma pactuação que considerasse a realidade locorregional e a assimetria dos municípios brasileiros.

Nesse contexto, foram constituídos sistemas municipais de saúde, com distintos potenciais resolutivos, atomizados e desarticulados, independentemente da capacidade de governo dos municípios para assumir esse papel. Agravando essa situação, os municípios contavam com precária cooperação e apoio técnicos das esferas estadual e federal.

Saliente-se que esse processo de descentralização da saúde é impregnado por distintas concepções, enfrentando contradições e conflitos. O projeto da reforma sanitária defendia a descentralização, em um contexto de rede- 
mocratização do país, enquanto uma estratégia para aproximar os serviços de saúde às necessidades dos cidadãos, de forma a ampliar espaços democráticos, a participação social e o poder local 5 . Em contrapartida, o projeto de reforma do Estado defendia a descentralização como estratégia de modernização da administração pública, reduzindo o papel do Estado e compartilhando responsabilidades com a sociedade e com o mercado 6,7 .

É importante considerar, ainda, que a descentralização pode se identificar com distintas ideologias, pois "cada um encontra na Descentralização aquilo que considera mais oportuno e conveniente encontrar" 8 (p. 333). Dessa forma, é fundamental reconhecer os atores sociais e suas ideologias, presentes em uma determinada conjuntura política, para que se possam identificar potências e limites da descentralização. A descentralização pode ser caracterizada como um modo de ser do aparelho político ou administrativo, apresentando-se sempre associada à centralização, como ordenamentos jurídicos na organização do Estado ${ }^{8}$.

Nesse sentido, dificilmente a descentralização é encontrada em seu estado puro ou é efetivada em sua radicalidade. Haverá sempre a coexistência com um grau variável de centralização, na dependência das forças políticas atuantes em cada momento histórico.

Considerando o desafio do SUS, a proposta de descentralização, que implica a transferência de poder e competências do nível central para os níveis locais, pressupõe a definição de novas competências para os entes federados envolvidos, bem como a organização de novas estruturas administrativas 9 . Para que esse novo arranjo seja efetivo, deve-se consolidar a capacidade de cada ente para executar novas funções e interagir com funções executadas pelas demais esferas de governo, mantendo um equilíbrio entre autonomia e interdependência 10 . A capacidade de gestão do nível local para assumir e conduzir com responsabilidade políticas sociais se constitui em uma das variáveis determinantes para a conformação que a descentralização assume em cada região ${ }^{1,11}$.

Apesar dos limites do processo de descentralização da saúde no Brasil 12,13 e as distintas ideologias presentes na arena do SUS, essa diretriz operacional continua sendo apontada como uma estratégia importante para viabilizar a implementação dos princípios do SUS. No entanto, pouco tem sido discutido sobre o desafio da descentralização, no âmbito intramunicipal, em municípios de grande porte.

Assim, este artigo tem como objetivo analisar o processo de descentralização do SUS, em seu âmbito intramunicipal, no Município de São Paulo.

\section{Métodos}

No Brasil, o município é identificado como o espaço onde se materializa o resultado da descentralização. Contudo, na medida em que esse processo envolve relações entre as três esferas de governo (município, estado e União), propõe-se que avaliações sobre a descentralização contemplem tais relações 12,14 .

O presente estudo, embora tenha o campo circunscrito ao espaço singular de um município, incorpora na análise e discussão elementos do espaço geral, relacionado ao contexto nacional e do espaço particular, referente ao contexto estadual.

A estratégia utilizada para o desenvolvimento da pesquisa foi o estudo de caso que é caracterizado como uma investigação empírica de um fenômeno contemporâneo complexo, em seu contexto, especialmente quando os limites entre o fenômeno e o contexto não estão claramente definidos 15 .

Em função da extensa dimensão territorial, populacional e, ainda, da complexidade da rede de serviços de saúde do Município de São Paulo, optou-se por delimitar o campo deste estudo a uma região desse município, que reunisse características compatíveis com um sistema local de saúde. Os principais critérios utilizados para essa seleção foram: existência de serviços públicos de saúde, em quantidade e de distintos níveis de complexidade, e existência de estrutura político-administrativa da saúde, no território. Por um processo de negociação junto à Secretaria Municipal de Saúde de São Paulo (SMS-SP), foi selecionada uma Supervisão Técnica de Saúde (STS). A pesquisa abarcou o período da gestão municipal de 2005-2008.

O território sob responsabilidade da STS selecionada coincide com o de uma Subprefeitura e tem uma população residente estimada em pouco mais de 430 mil habitantes. É importante considerar que, em termos populacionais, essa Subprefeitura é maior do que $96 \%$ dos municípios brasileiros, incluindo algumas capitais como Florianópolis (Santa Catarina) e Vitória (Espírito Santo) 16.

Nessa região está situado um número significativo de serviços públicos de saúde, sob gestão municipal: 19 unidades básicas de saúde (UBS); 1 ambulatório de especialidades; 1 Centro de Atenção Psicossocial para criança e adolescente; 1 serviço de atendimento especializado em DST/AIDS; 2 Centros de Especialida- 
des Odontológicas; 4 unidades de assistência médica ambulatorial; 1 pronto-socorro; 1 laboratório clínico. Além desses, existem outros serviços públicos que se encontram sob dupla gestão, da Secretaria de Estado da Saúde de São Paulo (SES-SP) e da SMS-SP: 1 Núcleo de Gestão Ambulatorial (ambulatório de especialidades); 1 Hospital de Especialidades Estadual com 404 leitos; 1 hospital de especialidades com 241 leitos e ambulatório de especialidades anexo; e 1 hospital psiquiátrico.

As principais fontes de evidência utilizadas foram: entrevistas não estruturadas com informantes-chaves, selecionados entre os gestores da SMS-SP e documentos da gestão (decretos, resoluções, documentos elaborados pelas equipes regionais). Os entrevistados foram esclarecidos sobre o tema central e, após uma livre explanação, responderam a perguntas específicas sobre temas não abordados na fala inicial e de interesse para a pesquisa. Foram entrevistados o supervisor da STS selecionada e dois coordenadores de Coordenadorias Regionais de Saúde (CRS), sendo um deles da CRS correspondente à STS selecionada. As entrevistas foram gravadas e, posteriormente, transcritas por assistentes de pesquisa.

Pelo trabalho de campo foram identificadas e construídas categorias empíricas que possibilitassem uma melhor apreensão da realidade em estudo: capacidade de gestão locorregional e poder de decisão do gestor locorregional. Para a análise, utilizou-se o referencial teórico do triângulo de governo ${ }^{17}$ enquanto categoria analítica. É importante registrar que o conceito de triângulo de governo está relacionado com o ato de governar e exige a articulação de três variáveis: projeto de governo, capacidade de governo e governabilidade do sistema 17.

Segundo Vieira-da-Silva et al. 12, que utilizaram esse referencial para elaborar um modelo teórico-lógico para analisar a implantação da gestão descentralizada da saúde, a articulação efetiva entre os componentes do triângulo de governo no processo de descentralização levaria ao fortalecimento do poder local, das instituições públicas e da capacidade de gestão dos sistemas de saúde.

O projeto de pesquisa foi aprovado pelos Comitês de Ética em Pesquisa da Faculdade de Saúde Pública da Universidade de São Paulo e da SMS-SP, com base na Resolução no ${ }^{\circ}$. 196/96 do Conselho Nacional de Saúde.

\section{Resultados}

\section{O contexto da descentralização do SUS no} Município de São Paulo

No processo de (re)construção do SUS do Município de São Paulo, iniciado em 2001, a organização de Distritos de Saúde foi a estratégia assumida para operacionalizar a descentralização no âmbito intramunicipal. Essa ação setorial estava em consonância com a descentralização política e administrativa do governo municipal, que foi concretizada em 2002 com a criação de 31 Subprefeituras.

A Subprefeitura se constituiu como instância regional da administração direta, destacandose dentre suas atribuições: "planejar, controlar e executar os sistemas locais, obedecidas as politicas, diretrizes e programas fixados pela instância central da administração; (...) ampliar a oferta, agilizar e melhorar a qualidade dos serviços locais, a partir das diretrizes centrais; (...) facilitar o acesso e imprimir transparência aos serviços públicos, tornando-os mais próximos dos cidadãos" 18.

Esse projeto representava um avanço importante para a descentralização da administração municipal por seu potencial em aproximar a gestão aos espaços sub-regionais, possibilitando o planejamento e a administração regionalizados. Tal aproximação do poder público com o cidadão, estimulando a participação da população, contribuiria para o incremento da eficiência e eficácia das políticas públicas. As secretarias municipais seriam organismos de planejamento e coordenação das políticas gerais, o que garantiria a unidade municipal das ações governamentais. A execução e o gerenciamento das ações seriam realizados pelas Subprefeituras, por meio de coordenadorias que funcionariam como o poder público no território 19. Entretanto esse projeto de descentralização do governo municipal foi abandonado pela gestão municipal que iniciou em 2005.

Após a implantação das Subprefeituras, os Distritos de Saúde foram reestruturados e transformados em Coordenadorias de Saúde. Estas ficaram subordinadas administrativamente ao Gabinete do Subprefeito e tecnicamente à SMS-SP, ficando responsáveis "pelas ações de assistência à saúde, vigilância sanitária e epidemiológica, recursos humanos e financeiros da Saúde e atividades afins" 18.

Paralelamente à organização das Coordenadorias de Saúde, em 2002, foram criadas cinco Autarquias Hospitalares visando à modernização da gestão dos serviços hospitalares. Elas tinham como atribuição "a promoção e execução das ações e serviços de saúde de atenção médico- 
hospitalar" 20. As autarquias criadas assumiram a gestão das unidades hospitalares e de urgência e emergência próprias do município. Os hospitais públicos estaduais foram mantidos sob gestão da SES-SP, mesmo após o município assumir a Gestão Plena do Sistema de Saúde, em 2003.

Deve-se registrar, ainda, que as autarquias se constituíram enquanto instâncias autônomas, vinculadas diretamente ao Gabinete do Secretário, dissociadas política e administrativamente das Coordenadorias de Saúde, que seriam responsáveis pela implantação da política municipal de saúde em âmbito regional.

No início de uma nova gestão municipal, em 2005, a SMS-SP realizou uma reforma administrativa, por considerar que a estrutura vigente estava superdimensionada e, ainda, que a descentralização implementada no período anterior teria conduzido as coordenadorias a uma situação de excessiva autonomia em relação à SMS-SP, dificultando o comando único do SUS no município. Foram organizadas cinco novas CRS com base nas antigas Coordenadorias de Saúde, que foram reagrupadas e transferidas das Subprefeituras para a SMS-SP. Para dar funcionalidade às novas CRS, foram criadas 24 STS. Esse processo indica um movimento de (re)centralização da gestão da saúde no município.

Destaca-se que tanto as novas CRS, quanto as STS, foram criadas com estrutura mínima de cargos e pessoal e atribuições limitadas. As STS que são responsáveis por territórios populosos com cerca de 500 mil habitantes não apresentam sequer estrutura organizacional definida.

Essa reforma não contemplou mudanças nas Autarquias Hospitalares, mantendo-as com lógica e organização distintas e maior autonomia administrativa do que o restante da rede de serviços de saúde municipal. Embora os limites territoriais das novas coordenadorias fossem coincidentes com os das autarquias, observou-se a persistência da dificuldade de articulação entre as mesmas.

Outra questão importante do contexto político-institucional da SMS-SP, observada durante o período da pesquisa, foi uma significativa movimentação em seu quadro de direção. Na gestão 2005-2008, foram registradas três mudanças de secretários de saúde (quatro titulares) e, na região estudada, duas mudanças de coordenadores (três titulares) e quatro de supervisores (cinco titulares).

\section{A gestão do SUS locorregional}

Segundo documento de circulação interna, elaborado pela equipe técnica da CRS estudada, a SMS-SP estruturou as novas Coordenadorias visando restabelecer o comando técnico e operacional dos serviços ambulatoriais de saúde, vinculados administrativamente ao município. Essas CRS seriam responsáveis pela organização de um sistema regional de saúde e organizadas funcionalmente mediante Supervisões Técnicas de Saúde, que mantiveram as bases territoriais correspondentes às Subprefeituras. É importante frisar que não foram localizadas em qualquer outro texto oficial, incluso o decreto municipal 21 que dispõe sobre a reestruturação das Coordenadorias, indicações relativas à atribuição e à estrutura organizacional dessa estrutura administrativa de SMS-SP.

As STS, por sua vez, segundo informações contidas no documento supracitado, foram estruturadas de acordo com critérios populacionais, ou seja, cada supervisão abarcava um território com cerca de 500 mil habitantes. Elas deveriam supervisionar as atividades realizadas pelos serviços ambulatoriais do município, buscando promover sua integração com os demais serviços de saúde localizados em seu território.

Porém, a estrutura organizacional dessas STS não foi definida, nem tampouco foram criados cargos para as novas funções propostas. Pode-se identificar que na proposta de realocação e contratação de profissionais, contida no Planejamento Plurianual da CRS, a tabela de lotação de pessoal apresentada não contemplou as novas estruturas administrativas: coordenadoria e supervisões.

O supervisor de saúde entrevistado identificou a falta de estrutura como um limite importante para a gestão locorregional: “[a STS] é uma estrutura muito enxuta e muito centralizada. (...) Eu tenho uma equipe muito reduzida. (...) O meu organograma, eu estava desenhando ele outro dia, eu tenho o supervisor e o corpo de bombeiros embaixo. Eu não tenho uma estrutura administrativa, técnica, (...) são pessoas" (Supervisor).

Nota-se uma contradição entre a precária estrutura existente, reconhecida pelo próprio supervisor, e o discurso manifesto do coordenador, enfatizando a importância da STS para a gestão municipal: "a capilaridade da informação também não chega na porta, por isso que a supervisão para nós é o maior instrumento dessa gestão. (...) A supervisão foi o carro chefe dessa gestão" (Coordenador 1).

Essas falas traduzem perspectivas distintas desses atores quanto às atribuições da supervisão. Se por um lado, o coordenador destaca a importância dessa estrutura para a gestão, por outro, o supervisor aponta que, em decorrência dos limites impostos, o papel possível de se exercer na prática era ainda mais restrito do que o acom- 
panhamento do trabalho das unidades, proposto no documento.

O supervisor, considerando o potencial dos serviços de saúde existentes no território de abrangência de sua supervisão, reconhecia que para avançar na organização do SUS regional seria necessário que essa realidade se modificasse.

"Hoje, com a estrutura definida nessa administração, que eu não concordo muito, eu sou um fiscal, né? Eu tenho um gargalo também. Quer dizer, (...) eu simplesmente recebo instruções e fiscalizo minhas unidades" (Supervisor).

E, ainda, reforçando esse sentimento de impotência, esse mesmo entrevistado fez um desabafo: "Eu estou murado, a palavra é, eu sinto, a minha sensação hoje como supervisor é essa, é murado. Quer dizer, eu me viro com aquilo que eu tenho aqui e com as iniciativas de amigos" (Supervisor).

Pode-se constatar pelas entrevistas que a supervisão também não se constituía em espaço para o planejamento regional. Um dos relatos, concernente à organização regional do programa de DST/AIDS, ilustra bem essa situação: "São ambulatórios totalmente independentes, a conversação é rara. (...) Pela estrutura dos serviços a gente tem alguma definição. (...) Isso tudo, uma coisa que o vento molda. (...) Em momento nenhum, nós sentamos pra discutir isso. (...) E eu tenho certeza que o programa de AIDS avançaria muito se nós dividíssemos o bolo. (...) O programa municipal, estadual, nacional, ele é muito avançado, ele estimula isso. Mas a organização do sistema eu acho que deveria partir da supervisão" (Supervisor).

A baixa governabilidade da STS, aliada à inexistência de planejamento nesse nível, foi identificada pelo supervisor, inclusive no contexto dos projetos prioritários implementados pela própria SMS-SP. De acordo com seu relato, esse gestor não teve qualquer participação no processo de planejamento e definição na implantação de novos serviços em sua região, como, por exemplo, uma unidade de assistência médicoambulatorial.

"Fui informado: 'olha, então, o AMA [assistência médico-ambulatorial] $X$ não sai mais'. (...) $O$ AMA seria instalado em outro local. (...) Aí conversei com meu coordenador e ele falou: 'não sei, não tenho resposta para isso, é uma decisão. Esqueça o $X$, seu segundo AMA vai ser no $Y$ '. E eu cumpri ordens, esqueci o X e estamos esperando o Y como AMA, né?" (Supervisor).

Outro exemplo da baixa governabilidade, apontado pelos gestores, relacionava-se com a dificuldade para garantir a referência hospitalar. Observa-se muita semelhança entre os relatos de todos os entrevistados sobre os obstáculos en- frentados, no cotidiano da gestão, na tentativa de articulação dos serviços ambulatoriais com os hospitais.

Cabe registrar que, nesta pesquisa, abordouse apenas a relação com hospitais públicos, visto que os entrevistados se referiram exclusivamente a esses serviços. Isso, provavelmente, devido ao fato de que, na região estudada, os hospitais públicos se constituem em importante referência, se não a principal.

Alguns gestores relacionaram essa dificuldade de articulação à lógica de funcionamento da instituição hospital, que é auto-referenciada e, por vezes, não incorpora as necessidades de saúde da população e a demanda dos serviços ambulatoriais.

“O hospital gira em torno das suas próprias necessidades. Ele não está preocupado com a necessidade da população como um coletivo, ele tá preocupado com quem chega nele. (...) Os hospitais precisam ter essa consciência de que eles estão trabalhando para a rede básica, que, por sua vez, trabalha para a população. E não o inverso" (Coordenador 2).

Foram destacadas, ainda, questões relacionadas à política institucional e à estrutura político-administrativa da SMS-SP que contribuíam para, paradoxalmente, ampliar as dificuldades vivenciadas pelos gestores locorregionais na sua relação com os próprios hospitais municipais. A manutenção do arranjo organizacional da assistência hospitalar municipal por meio de autarquias é identificada, por um dos coordenadores de saúde entrevistado, como um obstáculo para a integração dos hospitais com os demais serviços de saúde vinculados à própria SMS-SP.

"Tem cinco autarquias e cinco coordenadorias. Mas não corresponde, porque as autarquias não foram construídas na lógica do território. Hospital não trabalha na lógica do território. E, [a autarquia] foi construída juntando hospitais. (...) A autarquia continua como uma cisão. (...) A divisão da coordenadoria e da autarquia não é nem por níveis de atenção, nem por tipos de atenção; por quem funciona 12 horas e quem funciona 24 horas" (Coordenador 2).

É oportuno lembrar que os limites territoriais das novas coordenadorias coincidiam com os das autarquias. No entanto, esse fato por si só não foi suficiente para superar ou mesmo minimizar a dificuldade de articulação entre os serviços de saúde vinculados a essas estruturas.

Por outro lado, as informações obtidas nas entrevistas indicam que a SMS-SP fez uma opção política de estabelecer relação preferencial com os hospitais próprios, apesar da existência de hospitais estaduais de grande porte na região. 
"Essa regulação se volta pra dentro da prefeitura. (...) Eu já encontro uma coordenação que quase (...) ignora os hospitais estaduais. O que me deixa numa situação muito difícil, porque eu só tenho os hospitais estaduais na região. Não tenho hospital municipal. (...) E a coordenação simplesmente tende a querer resolver os meus problemas com a rede municipal" (Supervisor).

O coordenador de saúde explicita claramente essa política: " $O$ [hospital] X não é nossa referência. (...) [A referência] é o [hospital] Z. Porque nós optamos inicialmente vaga com os da casa, (...) os municipais. Não vaga com os do território" (Coordenador 1).

É interessante ressaltar que outro gestor entrevistado menciona esse tema e assume uma postura crítica em relação a essa opção, a qual representa, na prática, um entrave para a integração entre os serviços.

“O próprio gestor municipal ainda não está com essa visão de que é o gestor do sistema. (...) Ele tem que olhar o sistema como um todo. Não adianta só ver o serviço municipal, entendeu? Tem que ver como um todo" (Coordenador 2).

Assim, ficou evidente que a organização do sistema de referência e contra-referência era definida centralmente, desconsiderando, inclusive, os recursos disponíveis em cada região. O supervisor não tinha poder de decisão e, sequer, espaço para discutir essa questão.

"Eu não tenho autonomia de ir à Secretaria 'Qual é o quadro de referência, como funciona isso? Prefiro o [hospital] W, que é mais perto'. Não é assim. Isso vem num e-mail: 'Sua referência é o [hospital] Z'. (...) Ele tá numa outra região" (Supervisor).

Como conseqüência dessa política, a STS estudada era compelida a encaminhar pacientes a um hospital municipal, localizado em outra STS, com acesso mais difícil para o usuário, apesar da existência de hospitais estaduais localizados em seu território. Tanto o gestor quanto o usuário do sistema vinham sofrendo, na prática, o impacto dessa centralização administrativa.

Nesse contexto, foi evidenciada a existência de mecanismos informais na negociação entre o gestor locorregional e gerentes de serviços. Independentemente da natureza administrativa do hospital, o contato pessoal foi destacado, em todas as entrevistas, como uma das ferramentas freqüentemente utilizadas.

"A relação com o [hospital] Yé muito no doméstico, nas relações individuais, quem conhece quem, amigo de quem, do plantão tal. (...) A relação como [hospital] Xé uma relação boa, (...) muito fácil. (...) A relação não é [pelo fato do] equipamento ser municipal, ser estadual. Tem passado um pouco pelas pessoas" (Coordenador 1).
Entretanto, apesar da aparente facilidade da negociação direta entre colegas, foram relatados alguns aspectos negativos decorrentes dessa prática.

"A gente vai trabalhando, 'comendo mingau pelas bordas', vai tentando. Você entra num hospital, onde você conhece um gerente. Isso é muito complicado. (...) Ainda é um trabalho muito difícil. Ele não é sistêmico. (...) Você consegue um trabalho hoje e, amanhã, muda não sei quem tá lá e você tem que começar tudo de novo" (Coordenador 2).

Um exemplo da fragilidade desses acordos foi citado pelo supervisor entrevistado. Em decorrência do conhecimento pessoal prévio, esse gestor e o gerente do ambulatório de especialidades, vinculado a um dos hospitais estaduais localizados no território da STS, pactuaram um acordo regional com objetivo de organizar o fluxo de pacientes entre os ambulatórios de especialidades da região. Por decisão do nível central da SES-SP, esse acordo foi rompido, o que representou um retrocesso para a organização do sistema de saúde regional.

"Uma enfermeira, que é uma das responsáveis pelo ambulatório do hospital, e um colega médico clínico que trabalha lá são grandes amigos de outras administrações. (...) Eles vieram me procurar oferecendo um apoio (...), abrindo portas. (...) Nós equacionamos uma pactuação local. (...) Isso funcionou durante mais ou menos um mês e meio. (...) Foi muito positivo, acredito, para os pacientes. (...) Só que, infelizmente, esse acordo acabou se rompendo no momento em que essa enfermeira, ela não tem autonomia pra decidir essas coisas. (...) Nós avançamos muito, foi muito interessante para a região. E, depois, nós retrocedemos à estaca inicial" (Supervisor).

\section{Discussão}

Com elementos destacados do cotidiano da gestão locorregional da saúde no Município de São Paulo, apresentam-se algumas reflexões sobre a potência e os limites da descentralização intramunicipal, apreendida enquanto uma estratégia operacional utilizada para facilitar a implementação dos princípios finalísticos do SUS.

Os achados da pesquisa evidenciaram a fragilidade da organização político-administrativa locorregional da SMS-SP, o que se constituiu em importante fator limitante para a operacionalização de diretrizes do SUS no município. É importante lembrar que o território sob responsabilidade de cada STS tem dimensão populacional e de serviços de saúde instalados maior do que a maioria dos municípios brasileiros, incluindo algumas capitais. 
A política de saúde implementada pela gestão municipal, no período estudado, limitou o papel e as responsabilidades das novas estruturas político-administrativas da SMS-SP. Foi atribuído às STS apenas o acompanhamento das unidades ambulatoriais de saúde e às coordenadorias o comando técnico e operacional da rede ambulatorial de saúde municipal. Dessa forma, independentemente de outros fatores, a governabilidade, tanto do coordenador regional, quanto do supervisor, foi constrangida a uma parcela dos serviços de saúde e não ao sistema local como um todo.

Coerente com a racionalização da administração, uma das diretrizes da gestão municipal, as STS foram instituídas sem um organograma definido e, ainda sem a criação de novos cargos. Com isso, a STS estudada foi organizada mediante critérios definidos pelo próprio supervisor, com funcionários de carreira, mas antes de tudo amigos, pessoas com "boa vontade" ou com interesses particulares para se manterem em cargos administrativos. A estrutura funcional da supervisão é um dos indicadores de sua capacidade de governo, na medida em que essa capacidade é dependente do capital teórico, instrumental e experiência da equipe 17 .

Aliada à informalidade da equipe técnica, evidenciou-se inexistência de práticas de planejamento locorregional. Os projetos eram definidos no nível central de SMS-SP e conduzidos pelo supervisor que, por sua vez, apresentava baixíssimo poder de interferência sobre os mesmos. O papel da supervisão era muito mais o de controle de serviços de saúde do que o de gestão do SUS em sua região. É importante ressaltar que o planejamento é considerado um dos componentes fundamentais para a determinação da capacidade de governo 17. A ampliação da capacidade de governo, por sua vez, é uma das condições necessárias para que as instâncias locais possam assumir as responsabilidades transferidas no processo de descentralização.

O relato de um coordenador regional corrobora essa análise. Este (Coordenador 2) assinala que "houve um movimento de centralização extremamente forte" da gestão municipal, uma vez que as decisões e ações propostas não respeitavam o incipiente planejamento locorregional. Decorrente dessa centralização observou-se o esvaziamento técnico e político das estruturas político-administrativas locorregionais da SMS-SP.

Apesar dos limites político-institucionais, identificou-se a mobilização do supervisor para ampliar sua governabilidade. As iniciativas protagonizadas por esse ator, como o acordo regional com um dos hospitais estaduais da região, não foram suficientes para modificar as relações de poder instituídas. É importante reconhecer que esses mecanismos de negociação informal, firmados entre colegas e não entre instituições, superam muitas vezes obstáculos e dificuldades de acesso a serviços especializados. No entanto, em que pese a importância desses acordos para a gestão do sistema de saúde, o caso estudado evidenciou que sua sustentação política e institucional, em um sistema complexo como o SUS, é frágil.

Deve-se considerar que a manutenção de hospitais sob gestão estadual representou, na prática, importante fator de limitação da governabilidade, inclusive para o gestor municipal do SUS. Apesar de o Município de São Paulo ter assumido a gestão plena do sistema de saúde, verificou-se que pouco se avançou para a efetiva integração dos hospitais ao sistema de saúde.

Essa dificuldade enfrentada pela SMS-SP na sua articulação com hospitais estaduais já foi evidenciada em outro estudo. Com base no caso de um hospital, da mesma região analisada nesta pesquisa, esse estudo identificou a subordinação de sua direção mais aos interesses político-partidários do que aos da política de saúde 22 .

A descentralização do SUS impõe um processo permanente de mediações políticas entre distintos gestores. À proporção que esses gestores atuam dirigindo, formulando estratégias, produzindo política, eles "conformam e constituem um campo de poder governamental em que ocorrem tensionamentos e mediações políticas contínuas e permanentes. Um campo de gestão permeado pelo poder institucional que opera sob a delegação e a tutela dos detentores de mandato executivo" 23 (p. 1146).

Registre-se que o tema da integração entre distintos serviços de saúde, em particular entre hospitais e serviços de atenção básica, ganhou relevância a partir do final da década de 1970. Desde essa época, a Organização Mundial da Saúde (OMS) e a Organização Pan-Americana da Saúde (OPAS) vêm promovendo discussões e se posicionando sobre a necessidade de definir o papel do hospital e sua integração a sistemas nacionais e locais de saúde. Destaca-se, nessa agenda, a relação do sistema local de saúde - Distrito de Saúde - com os hospitais. A imagem-objetivo dessa integração seria uma situação de equilíbrio - de poder, responsabilidades e recursos - entre o hospital e a rede básica de saúde, dependentes da autoridade ou governabilidade acumuladas pelo gestor do sistema local 24,25.

No Brasil, os hospitais, tanto públicos quanto privados, constituíram-se por um sistema próprio de normas e valores, desfrutando de considerável autonomia para definir sua clientela, organizar seu processo de trabalho e sua modalidade assistencial 26. Historicamente, 
constituíram-se como serviços hegemônicos, operados por profissionais das classes dominantes que sempre usaram seu prestígio político para resistir às mudanças 27 . Nesse contexto, até o momento, não foi implementada uma reforma sistêmica do modelo de atenção hospitalar brasileiro, optando-se por desencadear somente programas isolados, de caráter complementar, que não demonstram a possibilidade de um novo rumo 28.

Dessa forma, a articulação do hospital aos demais serviços de saúde é uma das questões estratégicas para a efetivação da integralidade da assistência no SUS, devendo ser priorizada na agenda política dos gestores, no processo de descentralização da saúde no município.

\section{Considerações finais}

Julgamos importante reafirmar que descentralização do SUS não deveria ser um fim em si mesmo e, também, que esta não se constitui nem panacéia, nem saída mágica para viabilizar a implantação de políticas públicas 7,12,13. Contudo, em que pesem os limites dessa descentralização, considera-se que essa diretriz constitui um meio para alcançar seus objetivos.
No Município de São Paulo, alguns desafios devem ser enfrentados para que se possa avançar no processo de descentralização da saúde. O primeiro grande desafio é assumir de fato a gestão de todo o sistema de saúde do município, o que significa assumir hospitais e ambulatórios que ainda permanecem sob a gestão centralizada da SES-SP.

É necessário avançar na descentralização da própria gestão municipal do SUS para estruturas político-administrativas, como aquelas correspondentes às STS. Esse processo deve ser implementado de forma a viabilizar a organização de um sistema descentralizado e com autonomia que mantenha o compromisso com a solidariedade e co-responsabilidade.

Para se enfrentar o desafio da descentralização em municípios de grande porte, é importante avaliar experiências internacionais como: Buenos Aires, Argentina; Montevidéu, Uruguai; Berlim, Alemanha; Paris, França; Barcelona, Espanha. Nessas metrópoles, foram conduzidos processos de descentralização político-administrativa de seus governos que viabilizaram a criação de estruturas regionais, com distintas configurações, responsáveis pela gestão da política municipal 29. Tais experiências podem apontar caminhos para que o processo de descentralização do SUS avance para além de uma política setorial isolada. 


\section{Resumo}

A descentralização do Sistema Único de Saúde (SUS) ainda enfrenta importantes desafios, em particular a busca de alternativas para grandes municípios. Por se caracterizar como um processo eminentemente politico, variáveis político-institucionais, dentre as quais se destaca a capacidade de gestão do nível local, são determinantes para a conformação da descentralização em cada contexto. Utilizando o referencial do triângulo de governo para avaliar a capacidade de gestão, realizou-se um estudo de caso, com o objetivo de analisar o processo de descentralização do SUS no Município de São Paulo, Brasil, a maior metrópole brasileira. Pela análise de entrevistas com gestores selecionados e documentos da gestão, identificou-se um movimento de centralização da saúde na gestão municipal 2005 2008, acompanhado do desconcerto das estruturas locorregionais da Secretaria Municipal de Saúde, o que resultou no esvaziamento técnico e político dessas instâncias. Apesar dos limites da descentralização, destaca-se sua potência enquanto estratégia operacional para alcançar os objetivos do SUS. Aponta-se a necessidade de retomar o processo de descentralização da saúde no Município de São Paulo que, além de avançar para instâncias locorregionais, esteja articulado à descentralização da gestão pública municipal.

Descentralização; Gestão em Saúde; Política de Saúde; Sistema Único de Saúde

\section{Referências}

1. Levcovitz E, Lima LD, Machado CV. Política de saúde nos anos 90; relações intergovernamentais e o papel das Normas Operacionais Básicas. Ciênc Saúde Coletiva 2001; 6:269-93.

2. Viana ALd'A, Heimann LS, Lima LD, Oliveira RG, Rodrigues SH. Mudanças significativas no processo de descentralização do sistema de saúde no Brasil. Cad Saúde Pública 2002; 18 Suppl:139-51.

3. Barata LRB, Tanaka OY, Mendes JDV. 15 anos de SUS: desafios e perspectivas. In: Conselho Nacional de Secretários e Saúde, organizador. Convergências e divergências sobre gestão e regionalização do SUS. Brasília: Conselho Nacional de Secretários e Saúde; 2004. p. 87-103.

4. Goulart FAA. Esculpindo o SUS a golpes de portaria... - considerações sobre o processo de formulação das NOBs. Ciênc Saúde Coletiva 2001; 6:292-8.

5. Campos GW. Efeitos paradoxais da descentralização no Sistema Único de Saúde do Brasil. In: Fleury S, organizador. Democracia, descentralização e desenvolvimento: Brasil \& Espanha. Rio de Janeiro: Editora FGV; 2006. p. 417-42.

\section{Colaboradores}

S. M. Spedo concebeu e planejou o estudo, levantou e analisou os dados e redigiu o artigo. N. R. S. Pinto e O.Y. Tanaka participaram da concepção e planejamento da pesquisa e colaboraram na análise e revisão do texto.

\section{Agradecimentos}

A pesquisa que deu origem a este artigo foi financiada (modalidade apoio à pesquisa) pela Fundação de Amparo à Pesquisa do Estado de São Paulo (FAPESP, processo $\mathrm{n}^{\circ}$. 05/53846-8) e Conselho Nacional de Desenvolvimento Científico e Tecnológico (CNPq, processo $\mathrm{n}^{\mathrm{o}}$. 401903/05-2).
6. Teixeira SMF. Descentralização dos serviços de saúde: dimensões analíticas. Rev Adm Pública 1990; 24:78-99.

7. Ase I. La descentralización de servicios de salud en Córdoba (Argentina): entre la confianza democrática y el desencanto neoliberal. Salud Colect 2006; 2:199-218.

8. Roversi-Monaco F. Descentralização e centralização. In: Bobbio N, Matteuci N, Pasquino G, organizadores. Dicionário de política. 7ạ Ed. Brasília: Universidade de Brasília; 1995. p. 329-35.

9. Abrucio FL. Para além da descentralização: os desafios da coordenação federativa no Brasil. In: Fleury S, organizador. Democracia, descentralização e desenvolvimento: Brasil \& Espanha. Rio de Janeiro: Editora FGV; 2006. p. 77-125.

10. Luz MT. Duas questões permanentes em um século de políticas de saúde no Brasil republicano. Ciênc Saúde Coletiva 2000; 5:293-312. 
11. Guimarães L. Modalidades de descentralización en el sector salud y sus contribuciones a la equidad: elementos fundamentales para la formulación de um marco normativo. Washington DC: Organización Panamericana de la Salud; 2001. (Serie Informes Técnicos, 76).

12. Vieira-da-Silva LM, Hartz ZMA, Chaves SCL, Silva GAP, Paim JS. Análise da implantação da gestão descentralizada em saúde: estudo comparado de cinco casos na Bahia, Brasil. Cad Saúde Pública 2007; 23:355-70

13. Guimarães L, Giovanella L. Entre a cooperação e a competição: percursos da descentralização do setor saúde no Brasil. Rev Panam Salud Pública 2004; 16:283-8.

14. Souza LEPF, Vieira-da-Silva LM, Hartz ZMA. Conferência de consenso sobre a imagem-objetivo da descentralização da atenção à saúde no Brasil. In: Hartz ZMA, Vieira-da-Silva LM, organizadores. Avaliação em saúde: dos modelos teóricos à prática na avaliação de programas e sistemas de saúde. Rio de Janeiro: Editora Fiocruz/Salvador: EdUFBA; 2005. p. 65-102.

15. Yin RK. Estudo de caso: planejamento e métodos. 3a Ed. Porto Alegre: Bookman; 2005.

16. Instituto Brasileiro de Geografia e Estatística. Contagem da população 2007. Rio de Janeiro: Instituto Brasileiro de Geografia e Estatística; 2007.

17. Matus C. Política, planejamento \& governo. Brasília: Instituto de Pesquisa Econômica Aplicada; 1993.

18. São Paulo. Lei no ${ }^{\circ}$ 13.399. Dispõe sobre a criação de Subprefeituras no Município de São Paulo e dá outras providências. Diário Oficial do Município de São Paulo 2002; 2 ago.

19. Fundação de Empreendimentos Científicos e Tecnológicos. Descentralização e poder local: a experiência das Subprefeituras no Município de São Paulo. São Paulo: Editora Hucitec; 2004.
20. São Paulo. Lei no. 13.271. Dispõe sobre a descentralização das ações e serviços de saúde no Município de São Paulo, com a criação de entidades autárquicas hospitalares de regime especial. Diário Oficial do Município de São Paulo 2002; 4 jan.

21. São Paulo. Decreto $n^{\circ}$. 46.209. Dispõe sobre a transferência das Coordenadorias de Saúde das Subprefeituras que especifica para a Secretaria Municipal de Saúde. Diário Oficial do Município de São Paulo 2005; 16 ago.

22. Gerschman S. A democracia inconclusa: um estudo da reforma sanitária brasileira. 2a Ed. Rio de Janeiro: Editora Fiocruz; 2004.

23. Lotufo M. Sistemas de direção e práticas de gestão governamental em secretarias estaduais de saúde. Rev Adm Pública 2007; 41:1143-63.

24. Lerbergue WV, Lafort Y. The role of the hospital in the district: delivering or supporting primary health care? Geneva: World Health Organization; 1990.

25. Tejada Pardo D. El hospital en los sistemas locales de salud. In: Paganini JM, Capote Mir RE, compiladores. Los sistemas locales de salud: conceptos, métodos, experiencias. Washington DC: Organización Panamericana de la Salud; 1990. p. 276-86. (Publicación Científica, 519).

26. Campos, GWS. Reforma da reforma: repensando a saúde. São Paulo: Editora Hucitec; 1992.

27. Mendes EV. O dilema da fragmentação ou integração dos serviços de saúde: por sistemas integrados de serviços de saúde. In: Mendes EV, organizador. Os grandes dilemas do SUS. Tomo II. Salvador: Editora Casa da Qualidade; 2001. p. 71-154.

28. Campos GWS. A clínica ampliada e compartilhada, a gestão democrática e redes de atenção como referenciais teórico-operacionais para a reforma do hospital. Ciênc Saúde Coletiva 2007; 12:849-59.

29. Santos UP, Barretta D, organizadores. Subprefeituras: descentralização e participação popular em São Paulo. São Paulo: Editora Hucitec; 2004.

Recebido em 28/Jul/2008

Versão final reapresentada em 20/Mar/2009

Aprovado em 20/Abr/2009 